\title{
Short Stature
}

National Cancer Institute

\section{Source}

National Cancer Institute. Short Stature. NCI Thesaurus. Code C118686.

Height greater than two standard deviations below the mean of the appropriate reference population for the age and sex of the individual. 